Review Article

\title{
Meta-Analysis of the Relationship between NM23 Expression to Gastric Cancer Risk and Clinical Features
}

\author{
Min Fang, Yifeng Tao, Zhimin Liu, Hao Huang, Min Lao, Lingsha Huang, and Bo Zhu \\ Department of Clinical Laboratory, The Affiliated Tumor Hospital of Guangxi Medical University, Nanning, Guangxi, China \\ Correspondence should be addressed to Bo Zhu; zhubogxnn@126.com
}

Received 13 December 2016; Accepted 12 February 2017; Published 16 March 2017

Academic Editor: Xin-yuan Guan

Copyright (C) 2017 Min Fang et al. This is an open access article distributed under the Creative Commons Attribution License, which permits unrestricted use, distribution, and reproduction in any medium, provided the original work is properly cited.

The prognostic value of reduced NM23 expression for gastric cancer (GC) patients is still contradictory. Thus, we conducted a meta-analysis to quantitatively evaluate the association of NM23 expression with GC risk and clinical features by analyzing 27 publications. The result of our meta-analysis indicated that NM23 expression is markedly reduced in gastric cancer tissues (OR $=3.15 ; 95 \% \mathrm{CI}=1.97-5.03 ; P<0.001)$. Furthermore, NM23 expression was negatively correlated with N stage, TNM stage, and histological grade. However, NM23 expression was not correlated with T stage, lymphatic invasion, vascular invasion, and 5-year overall survival rate. In conclusion, reduced NM23 expression correlated with gastric cancer risk, but its association with GC clinical features remains inconclusive. Therefore, large-scale and well-designed studies, which use uniform antibody and criterion of NM23 positive expression, are required to further validate the role of the NM23 in predicting GC progression.

\section{Introduction}

Gastric cancer (GC) is one of the most common gastrointestinal cancers and the second leading cause of cancer related death worldwide [1]. The incidence and mortality rate is especially high in Eastern Asia populations including China, Japan and Korea, which may be on account of a high prevalence of chronic Helicobacter pylori infection, diets rich in salt, and genetics background [2]. Although the clinical prognosis for GC has been improved by the development of early detection and adjuvant chemoradiotherapy, the 5-year overall survival (OS) rate for GC patients worldwide is still less than $25 \%$ [3]. Therefore, it is crucial to identify prognostic biomarker for GC and provide clinical treatment strategies to GC patients. Several previous reports showed that reduced expression of nonmetastatic protein 23 (NM23) correlates with tumor pathology and GC disease prognosis [4-6].

NM23 was initially found in metastatic cell lines by Steeg et al. in 1988 and was the first of what has become a field of over 20 known metastasis suppressor genes [7, 8]. In humans, there are 10 genes belonging to the NM23 gene family, of which the two most abundantly expressed are NM23-H1 and NM23-H2 that encode the A and B subunits of nucleoside diphosphate kinase, respectively [9]. The NM23 are involved in multiple-biological processes, such as cellular proliferation, differentiation, motility, and tumor metastasis [10]. Many studies exhibited that reduced expression of NM23 has been regarded as an indicator closely related to the metastasis of tumors, such as hepatocellular, gastric, and colon carcinoma $[4,11,12]$. In contrast, overexpression of NM23 is related to tumors, such as neuroblastoma [13], lymphoma [14], and lung tumor [15], suggesting that the significance of NM23 expression is different depending on cancer types and the NM23 isoforms. As for gastric cancer, numerous studies concerning the NM23 and GC have been performed; however, the results remain controversial. Chen et al. found that the NM23 protein expression was significantly related to lymph node and peritoneal metastasis [5]. On the other hand, some studies showed opposite results or no significant findings. Dhar et al. demonstrated that the overexpression of NM23 in the primary tumors correlated with tumor invasion, metastasis, and progression [16]. Radovic et al. found that NM23 protein expression did not correlate with lymphovascular invasion and lymph node metastases [17]. As the cited articles referred to the analysis were not distinguished NM23 isoforms, we performed a meta-analysis to evaluate whether reduced total NM23 expression is a risk factor for GC and determine its importance as a predictor 


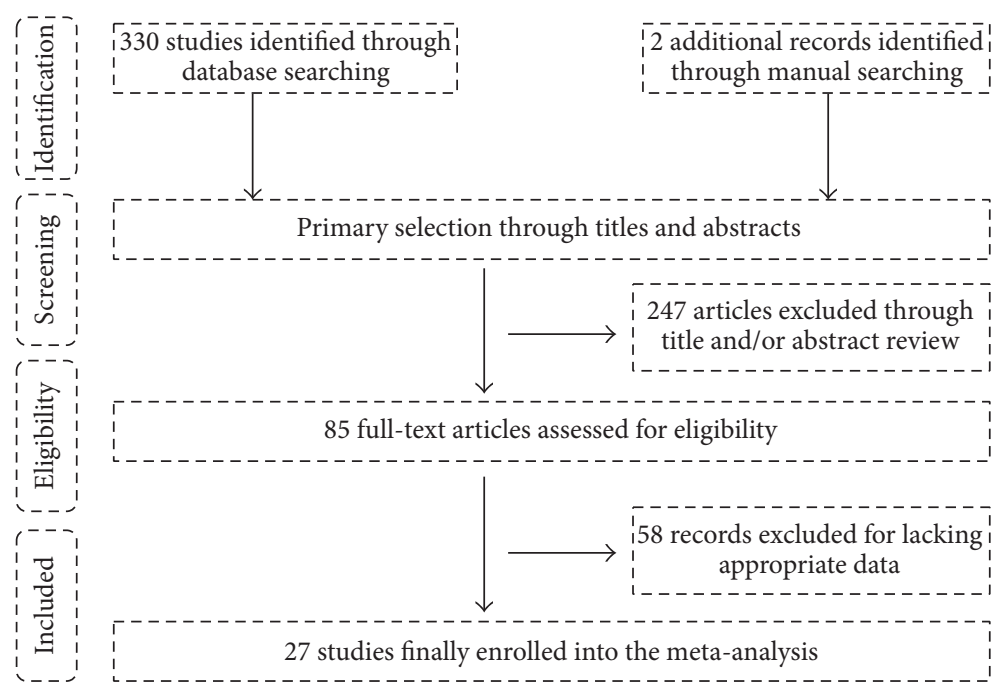

FIgURE 1: The flowchart of the study selection process.

of disease progression and prognosis of GC. To the best of our knowledge, this is the first comprehensive meta-analysis exploring the prognostic role of NM23 in GC patients.

\section{Materials and Methods}

2.1. Literature Search. We collected a systematic literature search from PubMed, Web of Science, and Embase database up to June 20, 2016. The following search terms were used: "gastric cancer", "gastric carcinoma" or "stomach neoplasms" and "NM23". We further performed a manual search to identify additional relevant papers.

2.2. Study Selection. Published articles were enrolled in our meta-analysis if they conformed to the inclusion criteria: (1) clear data were presented and related to an association between NM23 expression, clinical characteristics, and 5-year OS rate of GC patients; (2) the studies contained adequate published data; (3) it was published as a full-text article restricted to English or Chinese.

2.3. Data Extraction. All data from the eligible studies were extracted by two independent investigators with a predefined table. For every eligible study, information collected included the following: the first author's name, publication year, original country, TNM stage of patients, methods for detecting NM23, and 5-year OS rate. We first estimated the association between NM23 expression and GC risk. Moreover, we mainly examined the association between NM23 expression and clinical factors, including $\mathrm{T}$ stage, $\mathrm{N}$ stage, histological grade, lymphatic invasion, vascular invasion, TNM stage, and 5-year OS rate.

2.4. Statistical Analysis. The strength of the association between the NM23 expression and GC risk or clinical factors were estimated by OR with the corresponding 95\% CI. In the course of data pooling, statistical heterogeneity was evaluated by using $Q$-test and $I^{2}$ test [18]. A $P$ value $<0.10$ and/or $I^{2}>50 \%$ are considered significant heterogeneity, and then a random-effect model is employed. Otherwise, a fixed-effect model is used. Furthermore, we assessed publication bias with funnel plot and Egger's linear regression test [19]. $P$ value $\leqslant 0.05$ was considered statistically significant. Statistical analyses were performed with STATA software version 12.0.

\section{Results}

3.1. Study Selection and Characteristics. Systematic database literature search and complementary manual search retrieved a total of 332 relevant articles. After the titles and abstracts were scanned, 247 of the articles were excluded because they were duplicates and unrelated to the research topic. Through reading the remaining articles, 58 studies were excluded because they were nonhuman experiments and nonoriginal full articles and did not provide the appropriate data. Eventually, a total of 27 cohort studies [4-6, 16, 17, 2041] were enrolled into the analysis. The flow diagram of the study selection process was shown in Figure 1 and the main characters of the 27 studies were summarized in Table 1.

\subsection{Reduced NM23 Expression Correlated with Gastric Cancer} Risk. There were 5 studies evaluating NM23 expression with GC risk. The results of correlation between NM23 expression and the risk of GC were shown in Figure 2. In general, our study indicated that NM23 expression was statistically significantly declined in gastric cancer patients compared with noncancer controls $(\mathrm{OR}=3.15,95 \% \mathrm{CI}=1.97-5.03, P<$ $0.001)$. It is worth mentioning that the degree of heterogeneity was apparent among these studies.

3.3. Association between Reduced NM23 Expression and Clinical Features of GC Patient. Pooled ORs for NM23 expression, presented in Figure 3 and Table 2, revealed that low NM23 protein levels correlated with $\mathrm{N}$ stage $(\mathrm{OR}=0.493,95 \% \mathrm{CI}=$ 
TABLE 1: Main characteristics of the eligible studies.

\begin{tabular}{|c|c|c|c|c|c|c|c|}
\hline \multirow{2}{*}{ Author } & \multirow{2}{*}{ Year } & \multirow{2}{*}{ Country } & \multirow{2}{*}{ Cohort } & \multirow{2}{*}{ Stage } & \multirow{2}{*}{ Methods } & \multicolumn{2}{|c|}{ 5-year OS rate } \\
\hline & & & & & & $\mathrm{NM}_{23}{ }^{+}$ & $\mathrm{NM} 23^{-}$ \\
\hline Wang & 2016 & China & 230 & NA & IHC & & \\
\hline Radovic & 2013 & Croatia & 56 & I-IV & IHC & & \\
\hline Okayama & 2009 & Japan & 135 & I-III & IHC & & \\
\hline Yang & 2008 & China & 40 & I-IV & IHC & & \\
\hline Mönig & 2007 & Germany & 116 & I-IV & IHC & $35.80 \%$ & $40.00 \%$ \\
\hline Guan-Zhen & 2007 & China & 71 & I-IV & IHC & & \\
\hline Ding & 2006 & China & 78 & I-IV & ISH & $53.70 \%$ & $4.17 \%$ \\
\hline Yu & 2006 & China & 74 & NA & IHC & & \\
\hline Liu & 2005 & China & 40 & II/III & ISH & & \\
\hline Chen & 2005 & China & 43 & I-IV & IHC & & \\
\hline Chen & 2004 & China & 43 & I-IV & IHC & & \\
\hline $\mathrm{Li}$ & 2003 & China & 110 & I-IV & IHC & $70.50 \%$ & $20.00 \%$ \\
\hline Lee & 2003 & Korea & 841 & I-IV & IHC & $64.50 \%$ & $79.70 \%$ \\
\hline Terada & 2002 & Japan & 103 & NA & IHC & $63.26 \%$ & $48.44 \%$ \\
\hline Ji & 2002 & China & 71 & I-IV & IHC & & \\
\hline Wang & 1999 & China & 97 & NA & IHC & & \\
\hline Hsu & 1999 & China & 24 & III & IHC & $31.57 \%$ & $6.90 \%$ \\
\hline Dhar & 1999 & Japan & 59 & I-IV & IHC & $11.96 \%$ & $54.06 \%$ \\
\hline Yoo & 1999 & Korea & 261 & II-III & IHC & $59.82 \%$ & $53.70 \%$ \\
\hline Wang & 1998 & China & 37 & NA & IHC & & \\
\hline Yeung & 1998 & Australia & 23 & NA & IHC & & \\
\hline Muller & 1998 & Germany & 529 & NA & IHC & & \\
\hline Wei & 1997 & China & 138 & I-IV & IHC & & \\
\hline Songun & 1996 & Holland & 105 & I-IV & IHC & & \\
\hline Ura & 1996 & Japan & 110 & NA & IHC & $77.50 \%$ & $41.50 \%$ \\
\hline Kim & 1995 & Korea & 101 & NA & IHC & & \\
\hline Zhang & 1995 & China & 88 & I-IV & IHC & & \\
\hline
\end{tabular}

NA, not available; OS, overall survival; IHC, immunohistochemistry; ISH, in situ hybridization.

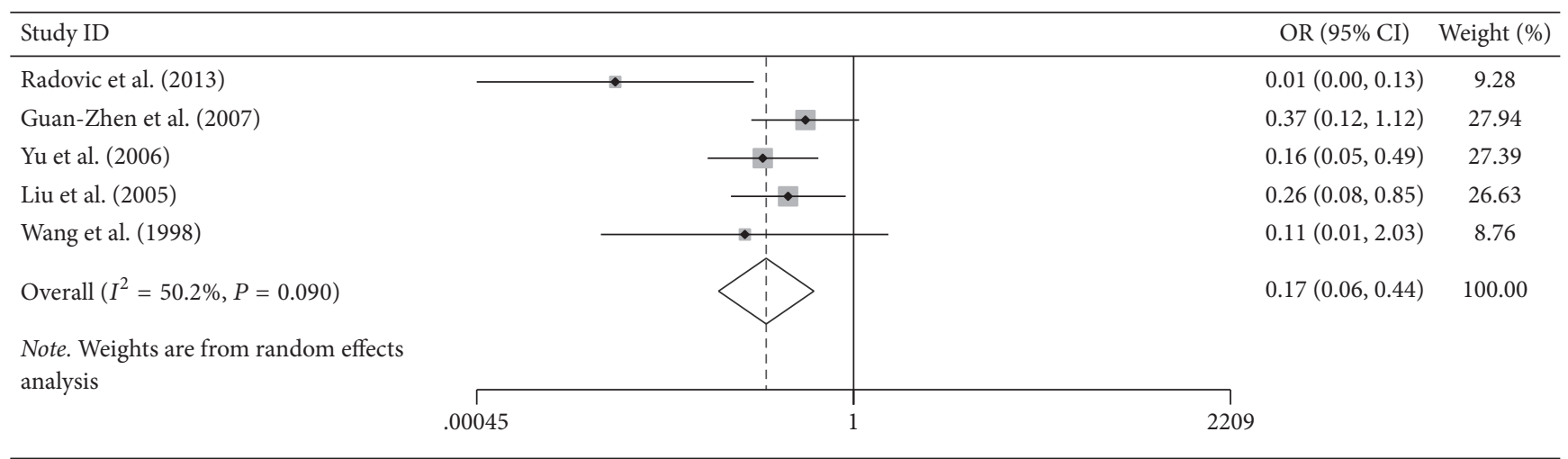

Figure 2: Association of NM23 expression with gastric cancer risk.

$0.269, P=0.904$, Figure $3(\mathrm{a}))$, TNM stage $(\mathrm{OR}=0.47,95 \% \mathrm{CI}$ $=0.32-0.70, P<0.001$, Figure $3(\mathrm{~b}))$, and histological grade $(\mathrm{OR}=0.476,95 \% \mathrm{CI}=0.32-0.71, P=0.055$ Figure $3(\mathrm{c}))$. However, no clear correlation was detected between NM23 expression and $\mathrm{T}$ stage $(\mathrm{OR}=0.889,95 \% \mathrm{CI}=0.50-1.583, P=$ 0.69 , Figure $3(d))$, lymphatic invasion $(\mathrm{OR}=0.801,95 \% \mathrm{CI}=$
$0.343-1.874, P=0.609$, Figure 3(e)), and vascular invasion $(\mathrm{OR}=0.902,95 \% \mathrm{CI}=0.429-1.899, P=0.787$, Figure 3(f)).

There were 9 cohorts with 1592 GC patients evaluating NM23 expression with 5-year OS rate. There was no correlation between NM23 expression and 5-year OS rate $(\mathrm{OR}=$ $0.478,95 \% \mathrm{CI}=0.194-1.181, P=0.11$ ) (Figure 4). 


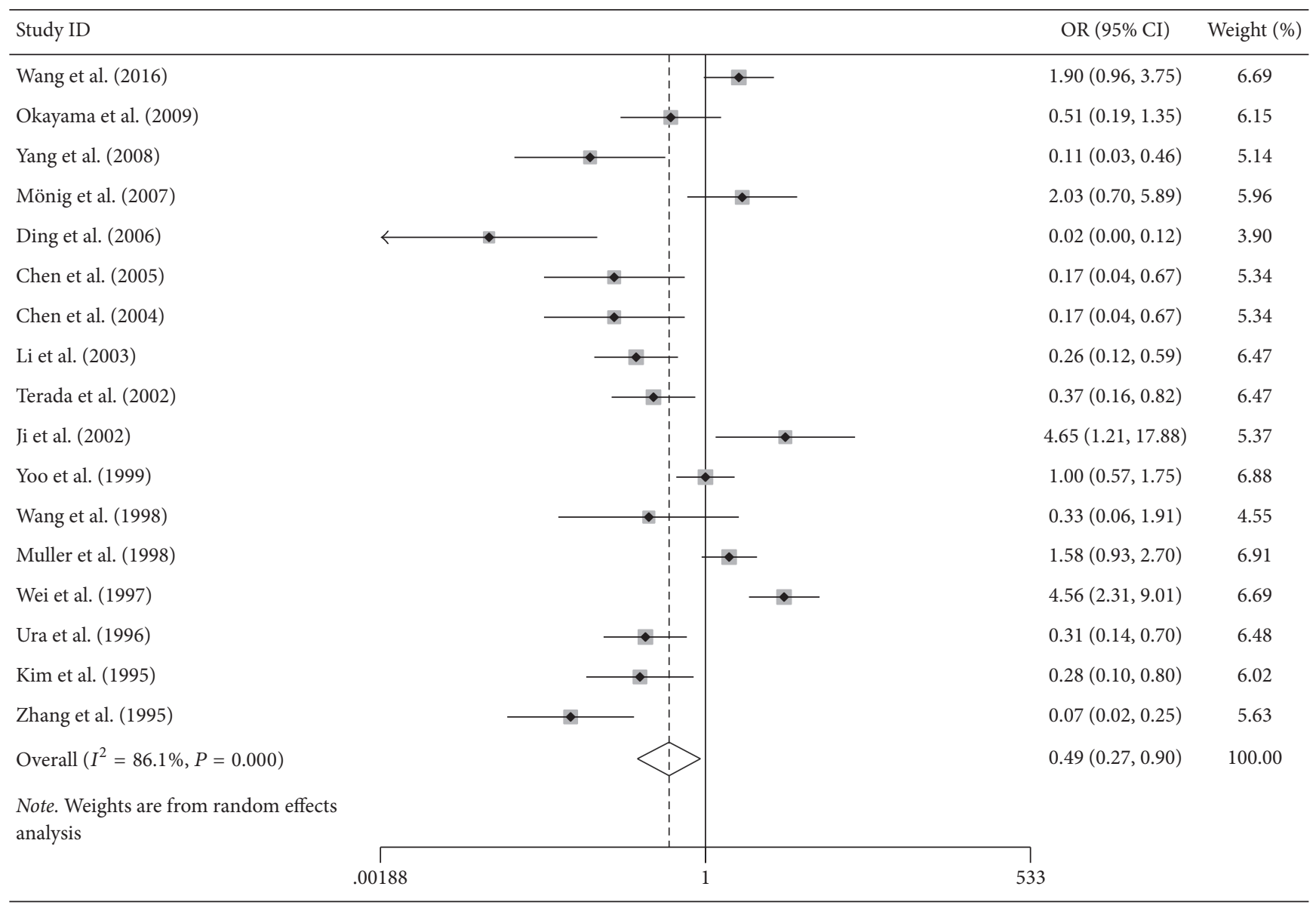

(a)

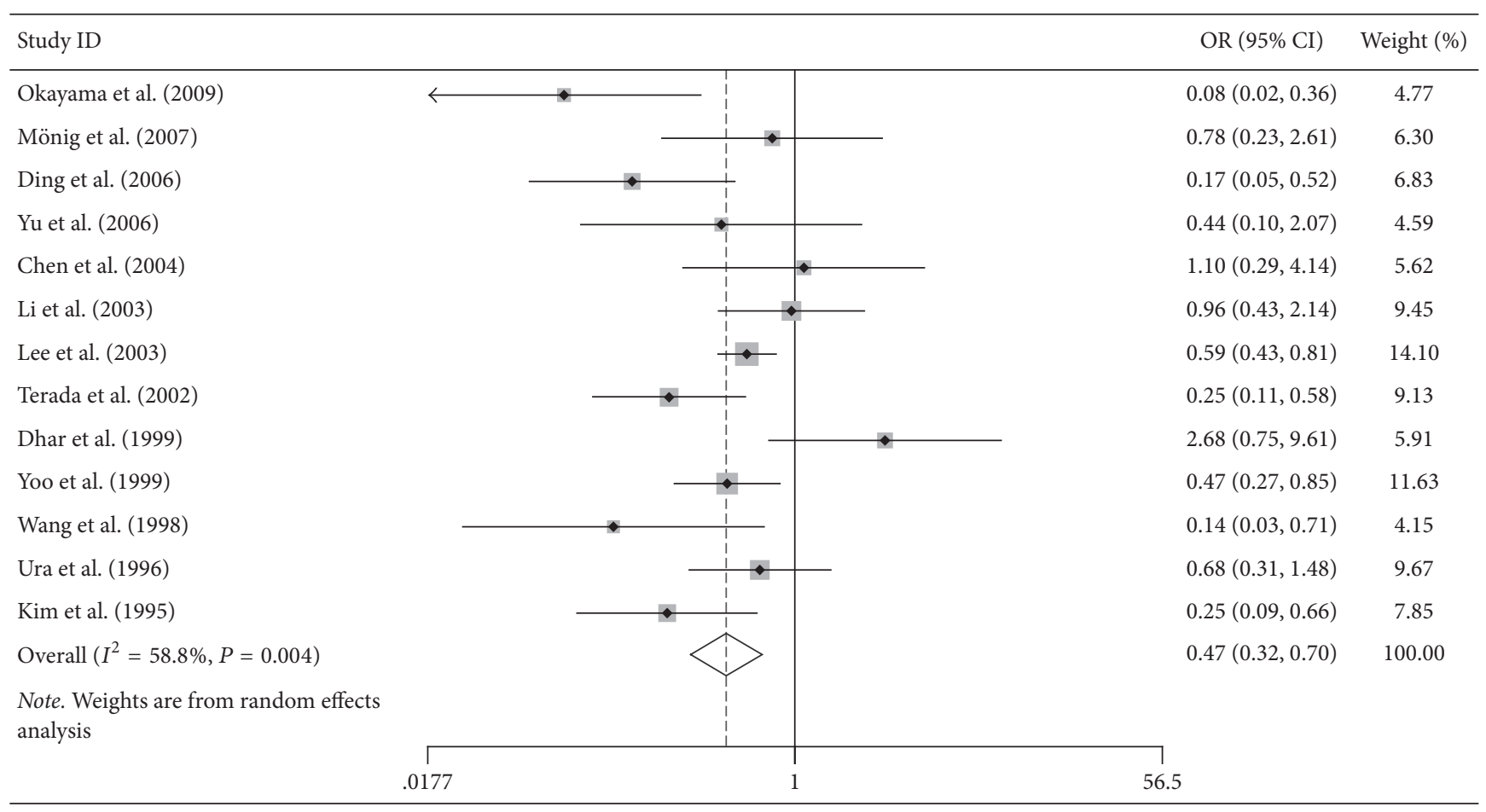

(b)

Figure 3: Continued. 


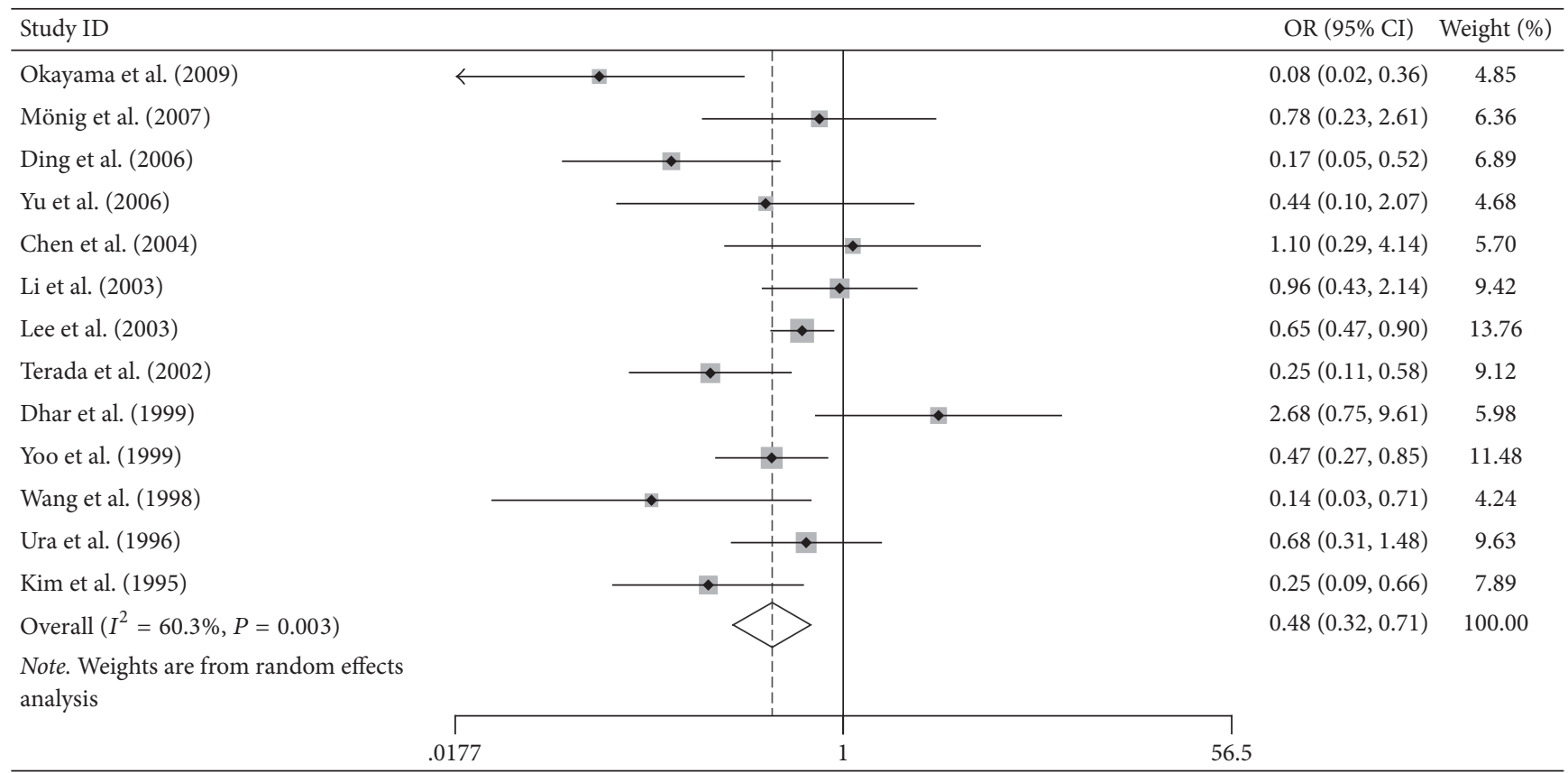

(c)

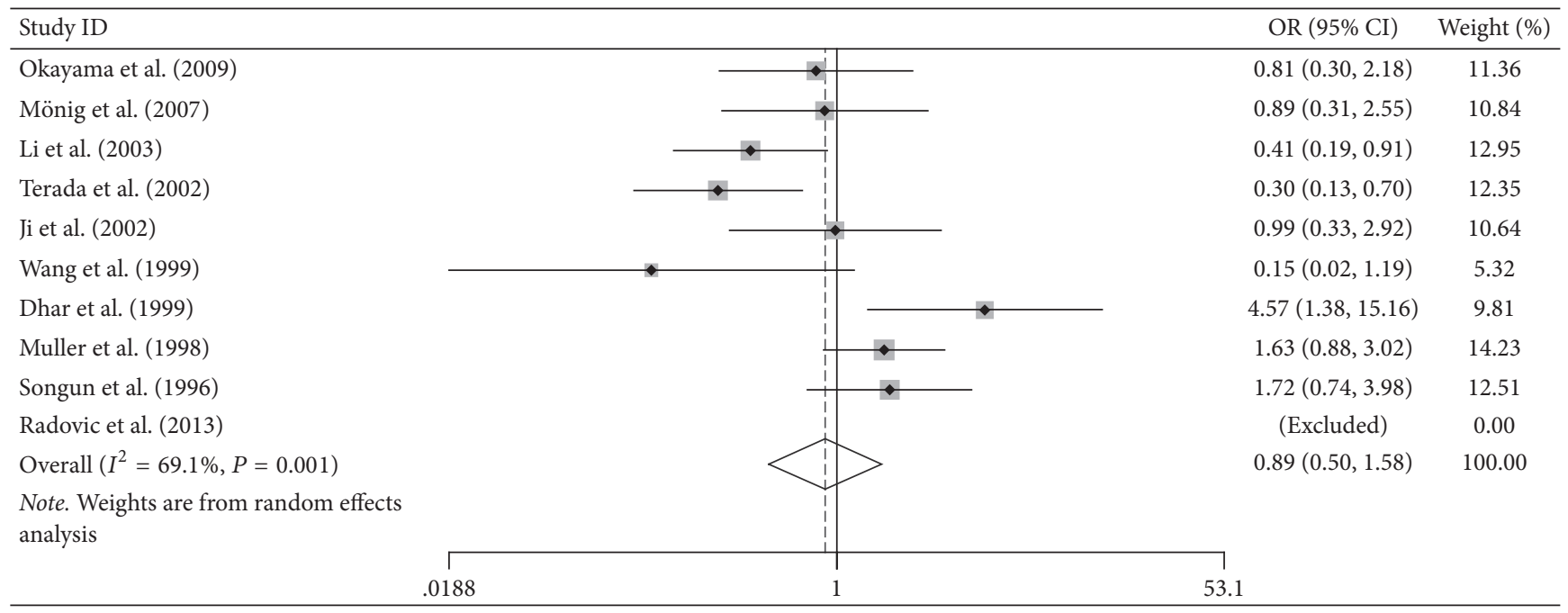

(d)

\begin{tabular}{|c|c|c|c|}
\hline Study ID & & OR (95\% CI) & Weight (\%) \\
\hline Okayama et al. (2009) & 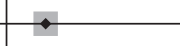 & $1.37(0.45,4.14)$ & 18.00 \\
\hline Terada et al. (2002) & & $0.35(0.15,0.84)$ & 20.43 \\
\hline Dhar et al. (1999) & & $0.79(0.03,20.37)$ & 5.41 \\
\hline Wang et al. (1998) & & $0.80(0.16,4.00)$ & 13.43 \\
\hline Muller et al. (1998) & $\longrightarrow$ & $2.24(1.27,3.95)$ & 23.24 \\
\hline Ura et al. (1996) & & $0.34(0.13,0.89)$ & 19.49 \\
\hline Overall $\left(I^{2}=73.0 \%, P=0.002\right)$ & & $0.80(0.34,1.87)$ & 100.00 \\
\hline \multicolumn{4}{|l|}{$\begin{array}{l}\text { Note. Weights are from random effects } \\
\text { analysis }\end{array}$} \\
\hline $\begin{array}{c}{ }^{\circ} \\
.0307\end{array}$ & 1 & & \\
\hline
\end{tabular}

(e)

Figure 3: Continued. 


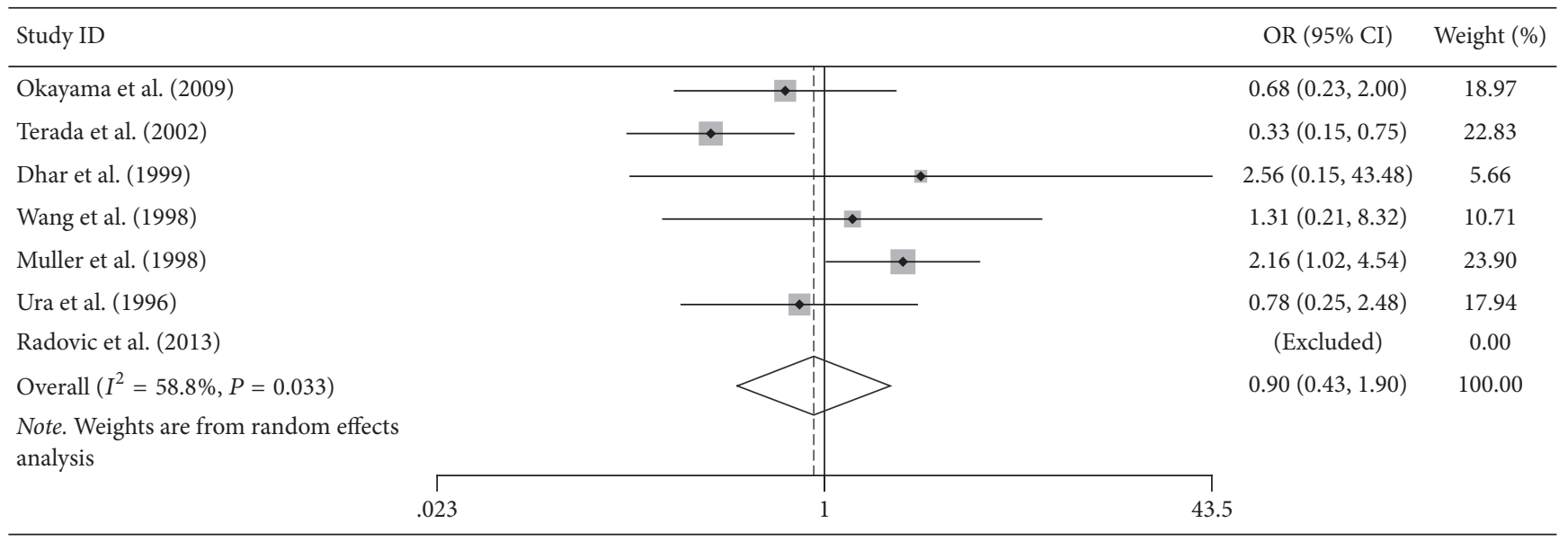

(f)

Figure 3: Association of NM23 expression with clinical features. (a) N stage; (b) TNM stage; (c) histological grade (d) T stage; (e) lymphatic invasion; (f) vascular invasion. Reduced NM23 expression was associated with TNM stage and histological grade. However, no significant correlation was found with the other clinical parameters analyzed.

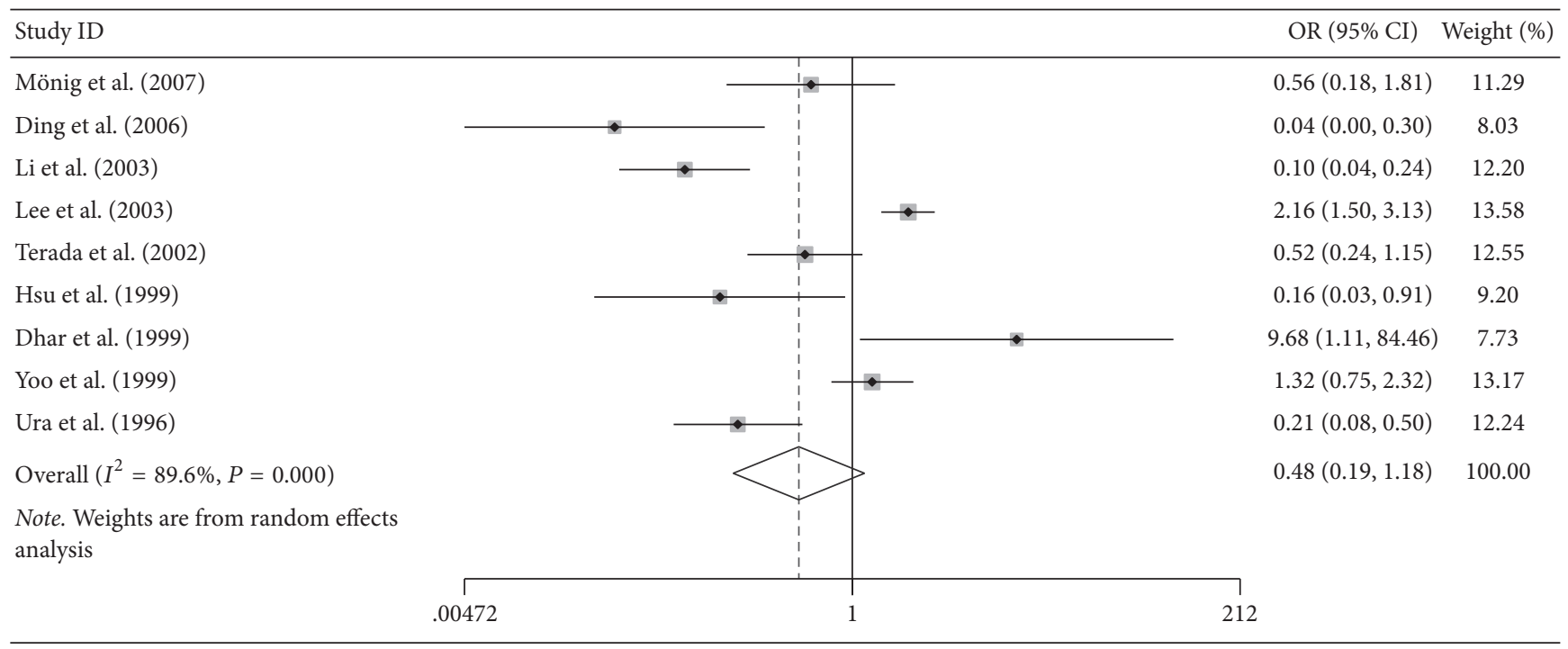

FIGURE 4: Association between NM23 expression and 5-year OS rate.

TABLE 2: Overall analysis of CD133 expression association with clinical features.

\begin{tabular}{|c|c|c|c|c|c|}
\hline & OR & $95 \% \mathrm{CI}$ & $P$ & $I^{2}$ & $P_{\text {bias }}$ \\
\hline Gastric cancer risk & 0.168 & $0.063-0.443$ & $<0.001$ & $50.20 \%$ & 0.134 \\
\hline $\mathrm{N}$ stage & 0.493 & $0.269-0.904$ & 0.022 & $86.10 \%$ & 0.052 \\
\hline TNM stage & 0.47 & $0.32-0.70$ & $<0.001$ & $82.20 \%$ & 0.401 \\
\hline Histological grade & 0.476 & $0.319-0.711$ & 0.001 & $60.30 \%$ & 0.294 \\
\hline T stage & 0.889 & $0.500-1.583$ & 0.690 & $69.10 \%$ & 0.606 \\
\hline Lymphatic invasion & 0.801 & $0.343-1.874$ & 0.609 & $73.00 \%$ & 0.437 \\
\hline Vascular invasion & 0.902 & $0.429-1.899$ & 0.787 & $58.80 \%$ & 0.835 \\
\hline 5-Year OS rate & 0.478 & $0.194-1.181$ & 0.110 & $89.60 \%$ & 0.074 \\
\hline
\end{tabular}

$P_{\text {bias }}$, the $P$ value of Egger linear regression test for evaluating publication bias. 
3.4. Sensitivity Analysis and Publication Bias. Sensitivity analysis was conducted through the sequential omission of individual studies. Except that for 5-year OS rate for the NM23 analysis, no single study could change the results, demonstrating that the results of our meta-analysis were quite credible. Moreover, the Egger regression test confirmed the absence of publication bias (Table 2).

\section{Discussion}

NM23 is the first discovered metastasis suppressor gene, which does not influence primary tumor growth but is a powerful inhibitor of metastatic spread of tumors [11]. NM23 is a nucleoside diphosphate kinase, which is thought to be critical for maintenance of intracellular nucleotide homeostasis as a housekeeping function [42]. NM23 also has other enzymatic activities such as histidine kinase, transcriptional activation, and exonuclease activities [43]. NM23 plays a critical role in cell differentiation, adhesion, apoptosis, migration, polymerization, signal transduction pathway, and vascular invasion [44]. Altered NM23 expression was found to be closely related to various tumor metastases, including GC. Several previous reports showed that reduced expression of NM23 correlates with tumor pathology and GC disease prognosis. Chen et al. and Hsu et al. found that the NM23 expression was significantly related to lymph node metastasis $[5,6]$. However, it remains controversial despite the numerous independent studies.

To the best of our knowledge, this is the first comprehensive meta-analysis exploring the role of NM23 in GC patients. Our study illustrated that reduced NM23 expression was correlated with elevated gastric cancer risk. And our results suggest that low NM23 levels correlated with higher $\mathrm{N}$ stage, worse TNM stage, and poor tumor differentiation grade. However, NM23 levels was not correlated with T stage, lymphatic invasion, vascular invasion, and 5-year OS rate. Overall, it was difficult to firmly establish that the reduced NM23 expression represents a prognostic biomarker for gastric cancer. This would require a larger data set from well-designed studies.

There was no correlation between NM23 expression and 5 -year OS rate when we included Lee et al. study. After eliminating the Lee et al. study, the 5-year rate of GC was significantly lower in gastric cancer patients in reduced NM23 expression group than patients with elevated NM23 expression. As Lee et al. study had large sample size and heterogeneity still existed when eliminating the Lee et al. study, it is difficult to make a definite conclusion on the prognostic value of NM23 expression among GC patients. Larger sample size studies from multicenter are needed to further explore this issue.

Although our study revealed the reduced NM23 expression correlated with GC risk, NM23 on predicting prognosis and clinicopathological parameters in GC patients need to be deliberately interpreted. Briefly, the sample size of the included studies was relatively small. Moreover, the criterion of positive NM23 expression was not uniformly defined. Furthermore, we estimated the 5-year OS from Kaplan-Meier curves in some original study, which might be less reliable than the data given by the original paper. What is more, large heterogeneity still remained in some analysis. Finally, owing to only including English and Chinese articles, there might be language bias in some ways. Additionally, positive reports are inclined to be published, which might make certain bias.

\section{Conclusion}

Our meta-analysis indicated that NM23 expression may generally be associated with the gastric cancer risk, but we were unable to determine if NM23 is a potential marker on predicting prognosis and clinicopathological parameters in GC patients. Large-scale and well-designed studies, which use uniform antibody and criterion of NM23 positive expression, are therefore required to further validate the role of the NM23 in predicting gastric cancer progression.

\section{Competing Interests}

The authors declare that there is no conflict of interests regarding the publication of this paper.

\section{Authors' Contributions}

Bo Zhu and Min Fang conceived and designed the experiments; Min Fang, Yifeng Tao, Zhimin Liu, and Hao Huang analyzed data; Min Fang, Bo Zhu, Min Lao, and Lingsha Huang wrote the manuscript. All authors reviewed and approved the manuscript. Min Fang and Yifeng Tao contributed equally to this work.

\section{Acknowledgments}

The work is supported by the Natural Science Foundation of Guangxi Medical University Programs, GXMUYSF201630.

\section{References}

[1] L. A. Torre, F. Bray, R. L. Siegel, J. Ferlay, J. Lortet-Tieulent, and A. Jemal, "Global cancer statistics, 2012," CA Cancer Journal for Clinicians, vol. 65, no. 2, pp. 87-108, 2015.

[2] M. Zhang, K. Liu, F. Wang, X. Wen, and X. Song, "Association between CYP2E1 polymorphisms and risk of gastric cancer: an updated meta-analysis of 32 case-control studies," Molecular and Clinical Oncology, vol. 4, no. 6, pp. 1031-1038, 2016.

[3] J. A. Ajani, "Gastroesophageal cancers: progress and problems," Journal of the National Comprehensive Cancer Network, vol. 6, no. 9, pp. 813-814, 2008.

[4] Y. Guan-Zhen, C. Ying, N. Can-Rong, W. Guo-Dong, Q. JianXin, and W. Jie-Jun, "Reduced protein expression of metastasisrelated genes (nm23, KISS1, KAI1 and p53) in lymph node and liver metastases of gastric cancer," International Journal of Experimental Pathology, vol. 88, no. 3, pp. 175-183, 2007.

[5] J.-Q. Chen, W.-H. Zhan, Y.-L. He et al., "Expression of heparanase gene, CD44v6, MMP-7 and nm23 protein and their relationship with the invasion and metastasis of gastric carcinomas," World Journal of Gastroenterology, vol. 10, no. 6, pp. 776782, 2004. 
[6] N.-Y. Hsu, K.-C. Chow, W.-J. Chen, C.-C. Lin, F.-F. Chou, and C.-L. Chen, "Expression of nm 23 in the primary tumor and the metastatic regional lymph nodes of patients with gastric cardiac cancer," Clinical Cancer Research, vol. 5, no. 7, pp. 1752-1757, 1999.

[7] P. S. Steeg, G. Bevilacqua, L. Kopper et al., "Evidence for a novel gene associated with low tumor metastatic potential," Journal of the National Cancer Institute, vol. 80, no. 3, pp. 200-204, 1988.

[8] J.-C. Marshall, J. Collins, N. Marino, and P. Steeg, “The Nm23H1 metastasis suppressor as a translational target," European Journal of Cancer, vol. 46, no. 7, pp. 1278-1282, 2010.

[9] M. Boissan, O. De Wever, F. Lizarraga et al., "Implication of metastasis suppressor NM23-H1 in maintaining adherens junctions and limiting the invasive potential of human cancer cells," Cancer Research, vol. 70, no. 19, pp. 7710-7722, 2010.

[10] M. Boissan, S. Dabernat, E. Peuchant, U. Schlattner, I. Lascu, and M.-L. Lacombe, "The mammalian Nm23/NDPK family: from metastasis control to cilia movement," Molecular and Cellular Biochemistry, vol. 329, no. 1-2, pp. 51-62, 2009.

[11] T. Yang, B.-Z. Chen, D.-F. Li et al., "Reduced NM23 protein level correlates with worse clinicopathologic features in colorectal cancers: a meta-analysis of pooled data," Medicine, vol. 95, no. 4, p. e2589, 2016.

[12] T. Nakayama, A. Ohtsuru, K. Nakao et al., "Expression in human hepatocellular carcinoma of nucleoside diphosphate kinase, a homologue of the nm23 gene product," Journal of the National Cancer Institute, vol. 84, no. 17, pp. 1349-1354, 1992.

[13] O. Takeda, M. Handa, T. Uehara et al., "An increased NM23H1 copy number may be a poor prognostic factor independent of LOH on 1p in neuroblastomas," British Journal of Cancer, vol. 74, no. 10, pp. 1620-1626, 1996.

[14] D. N. T. Aryee, I. Simonitsch, I. Mosberger et al., "Variability of nm23-H1/NDPK-A expression in human lymphomas and its relation to tumour aggressiveness," British Journal of Cancer, vol. 74, no. 11, pp. 1693-1698, 1996.

[15] S. Gazzeri, E. Brambilla, A. Negoescu et al., "Overexpression of nucleoside diphosphate/kinase $\mathrm{A} / \mathrm{nm} 23-\mathrm{H} 1$ protein in human lung tumors: association with tumor progression in squamous carcinoma," Laboratory Investigation, vol. 74, no. 1, pp. 158-167, 1996.

[16] D. K. Dhar, H. Kubota, H. Tabara et al., "nm23 in the primary and metastatic sites of gastric carcinoma. Relation to AFPproducing carcinoma," Oncology, vol. 56, no. 2, pp. 122-128, 1999.

[17] S. Radovic, M. Doric, A. Hukic, M. Babic, S. Kuskunovic, and N. Spahovic, "Immunohistochemical expression and significance of NM23 suppressor protein in primary gastric adenocarcinoma," Bosnian Journal of Basic Medical Sciences, vol. 13, no. 2, pp. 72-77, 2013.

[18] D. Jackson, I. R. White, and R. D. Riley, "Quantifying the impact of between-study heterogeneity in multivariate meta-analyses," Statistics in Medicine, vol. 31, no. 29, pp. 3805-3820, 2012.

[19] E. Zintzaras and J. P. A. Ioannidis, "HEGESMA: genome search meta-analysis and heterogeneity testing," Bioinformatics, vol. 21, no. 18, pp. 3672-3673, 2005.

[20] Y.-W. Wang, M.-L. Zhu, R.-F. Wang et al., "Predictable factors for lymph node metastasis in early gastric cancer analysis of clinicopathologic factors and biological markers," Tumor Biology, vol. 37, no. 7, pp. 8567-8578, 2016.

[21] H. Okayama, K. Kumamoto, K. Saitou et al., "CD44v6, MMP7 and nuclear $\mathrm{Cdx} 2$ are significant biomarkers for prediction of lymph node metastasis in primary gastric cancer," Oncology Reports, vol. 22, no. 4, pp. 745-755, 2009.

[22] S. P. Mönig, B. Nolden, T. Lübke et al., "Clinical significance of $\mathrm{nm} 23$ gene expression in gastric cancer," Anticancer Research, vol. 27, no. 4, pp. 3029-3033, 2007.

[23] Y.-Q. Yang, L. Wu, J.-X. Chen et al., "Relationship between $\mathrm{nm} 23 \mathrm{H} 1$ genetic instability and clinical pathological characteristics in Chinese digestive system cancer patients," World Journal of Gastroenterology, vol. 14, no. 36, pp. 5549-5556, 2008.

[24] G. F. Ding, J. C. Li, C. S. Li, Y. F. Xu, Y. Sun, and X. R. Chen, "Study on the correlation between the expressions of nm23H1 mRNA, VEGF-C mRNA and lymphatic metastases, survival rate with gastric cancer," Fen zi xi bao sheng wu xue bao = Journal of molecular cell biology / Zhongguo xi bao sheng wu xue xue hui zhu ban, vol. 39, no. 1, pp. 46-54, 2006.

[25] G.-Z. Yu, J.-J. Wang, Y. Chen, C.-R. Ni, and M.-H. Zhu, "Expressions of nm23, P53 and S100A4 proteins and their relationships with metastasis potential in gastric carcinoma," Chinese Journal of Gastrointestinal Surgery, vol. 9, no. 2, pp. 165169, 2006.

[26] Y.-J. Liu, P.-S. Yan, J. Li, and J.-F. Jia, "Expression and significance of CD44s, CD44v6, and nm23 mRNA in human cancer," World Journal of Gastroenterology, vol. 11, no. 42, pp. 6601-6606, 2005.

[27] J.-Q. Chen, W.-H. Zhan, Y.-L. He, S.-R. Cai, J.-S. Peng, and Z.-X. Chen, "Prediction of lymph node metastasis with binary logistic regression in gastric carcinoma," Chinese Journal of Gastrointestinal Surgery, vol. 8, no. 5, pp. 436-439, 2005.

[28] Y. Li, J.-H. Zhang, G. Kuang et al., "Expression of MUC1, CD44v6, nm23 in gastric carcinomas and regional lymph node tissues and their association with invasion, metastasis, and prognosis of the tumor," Ai zheng $=$ Aizheng $=$ Chinese journal of cancer, vol. 22, no. 9, pp. 985-989, 2003.

[29] K. E. Lee, H.-J. Lee, Y. H. Kim et al., "Prognostic significance of p53, nm23, PCNA and c-erbB-2 in gastric cancer," Japanese Journal of Clinical Oncology, vol. 33, no. 4, pp. 173-179, 2003.

[30] R. Terada, T. Yasutake, S. Nakamura et al., "Clinical significance of nm23 expression and chromosome 17 numerical aberrations in primary gastric cancer," Medical Oncology, vol. 19, no. 4, pp. 239-248, 2002.

[31] S.-Q. Ji, Y.-W. Hua, J. Zhuang et al., "Significance of COX-2, $\mathrm{p} 53$, proliferating cell nuclear antigen and $\mathrm{nm} 23$ expressions in gastric cancer and its behavior," Ai zheng = Aizheng = Chinese journal of cancer, vol. 21, no. 6, pp. 619-624, 2002.

[32] Y.-K. Wang, X.-L. Ji, and N.-X. Ma, "nm23 expression in gastric carcinoma and its relationship with lymphoproliferation," World Journal of Gastroenterology, vol. 5, no. 1, pp. 87-89, 1999.

[33] C. H. Yoo, S. H. Noh, H. Kim, H. Y. Lee, and J. S. Min, "Prognostic significance of CD44 and nm23 expression in patients with stage II and stage IIIA gastric carcinoma," Journal of Surgical Oncology, vol. 71, no. 1, pp. 22-28, 1999.

[34] C.-S. Wang, K.-H. Lin, Y.-C. Hsu, and S. Hsueh, "Distant metastasis of gastric cancer is associated with elevated expression of the antimetastatic nm23 gene," Cancer Letters, vol. 128, no. 1, pp. 23-29, 1998.

[35] P. Yeung, C. Soon Lee, P. Marr, M. Sarris, and D. Fenton-Lee, "Nm23 gene expression in gastric carcinoma: an immunohistochemical study," Australian and New Zealand Journal of Surgery, vol. 68, no. 3, pp. 180-182, 1998.

[36] W. Muller, A. Schneiders, G. Hommel, and H. E. Gabbert, "Expression of $\mathrm{nm} 23$ in gastric carcinoma: association with 
tumor progression and poor prognosis," Cancer, vol. 83, no. 12, pp. 2481-2487, 1998.

[37] Z. Wei, Y. Wu, and Z. Zhai, "Immunohistochemical study of p53, c-erbB-2 and nm23 proteins in human gastric cancer," Chinese Journal of Oncology, vol. 19, no. 5, pp. 378-381, 1997.

[38] I. Songun, C. J. H. Van De Velde, J. Hermans et al., "Expression of oncoproteins and the amount of eosinophilic and lymphocytic infiltrates can be used as prognostic factors in gastric cancer," British Journal of Cancer, vol. 74, no. 11, pp. 1783-1788, 1996.

[39] H. Ura, R. Denno, and K. Hirata, "The significance of nm23 protein expression in human gastric carcinomas," Surgery Today, vol. 26, no. 12, pp. 957-965, 1996.

[40] K. M. Kim, A. Lee, H. S. Chae, and S. I. Shim, "Expression of p53 and NDP-K/nm23 in gastric carcinomas-association with metastasis and clinicopathologic parameters," Journal of Korean Medical Science, vol. 10, no. 6, pp. 406-413, 1995.

[41] S. Zhang, S. Ye, and H. Lin, "Gastric cancer with P53 overexpression and nm23 low-expression has high potential for lymph node metastasis," Chinese Journal of Oncology, vol. 17, no. 6, pp. 418-421, 1995.

[42] P. Soliani, S. Ziegler, A. Romani et al., "Prognostic significance of $n m 23$ gene product expression in patients with colorectal carcinoma treated with radical intent," Oncology Reports, vol. 11, no. 6, pp. 1193-1200, 2004.

[43] N. Marino, J. Nakayama, J. W. Collins, and P. S. Steeg, "Insights into the biology and prevention of tumor metastasis provided by the Nm23 metastasis suppressor gene," Cancer and Metastasis Reviews, vol. 31, no. 3-4, pp. 593-603, 2012.

[44] C.-H. Lin, V. Dammai, B. Adryan, and T. Hsu, "Interaction between Nm23 and the tumor suppressor VHL," NaunynSchmiedeberg's Archives of Pharmacology, vol. 388, no. 2, pp. 143152, 2015. 


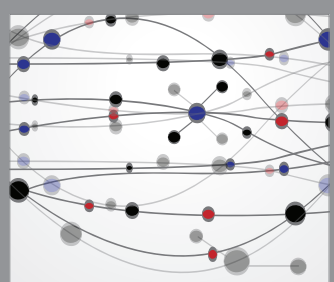

The Scientific World Journal
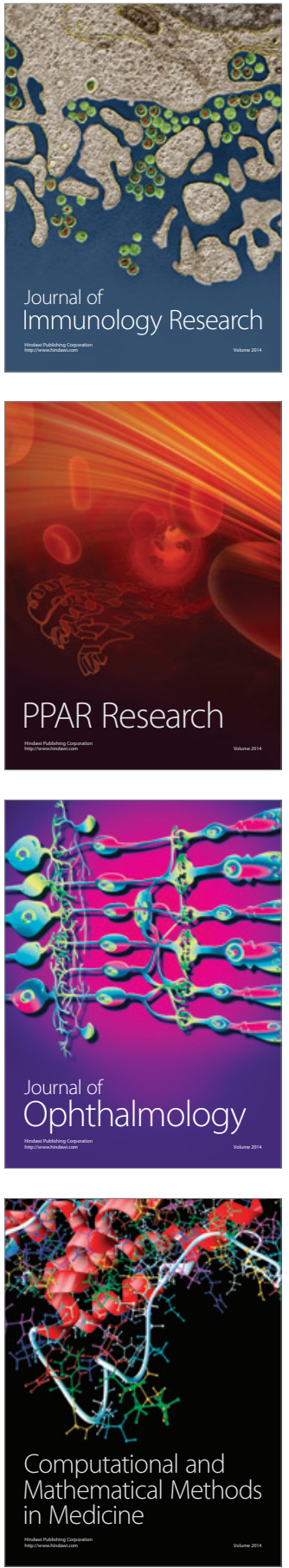

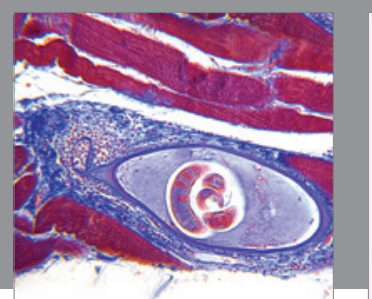

Gastroenterology Research and Practice
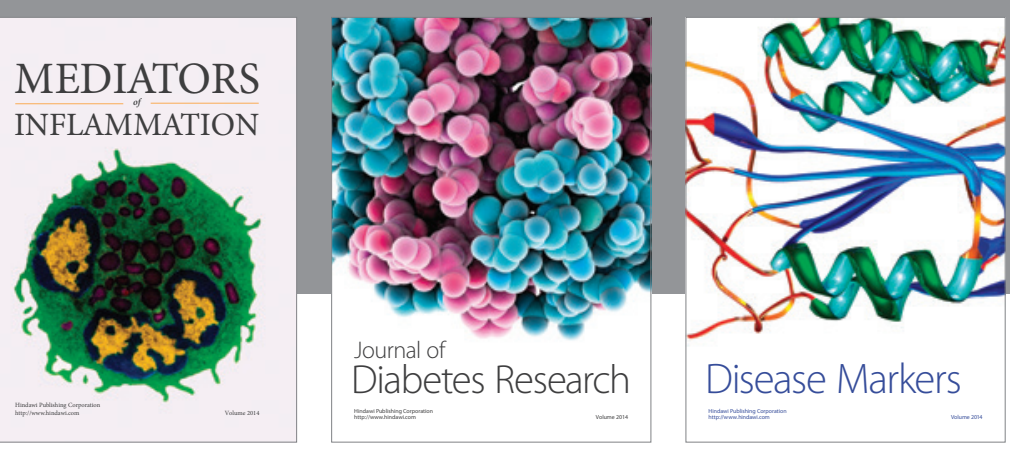

Disease Markers

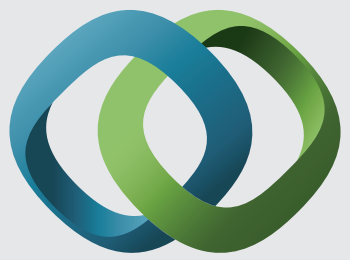

\section{Hindawi}

Submit your manuscripts at

https://www.hindawi.com
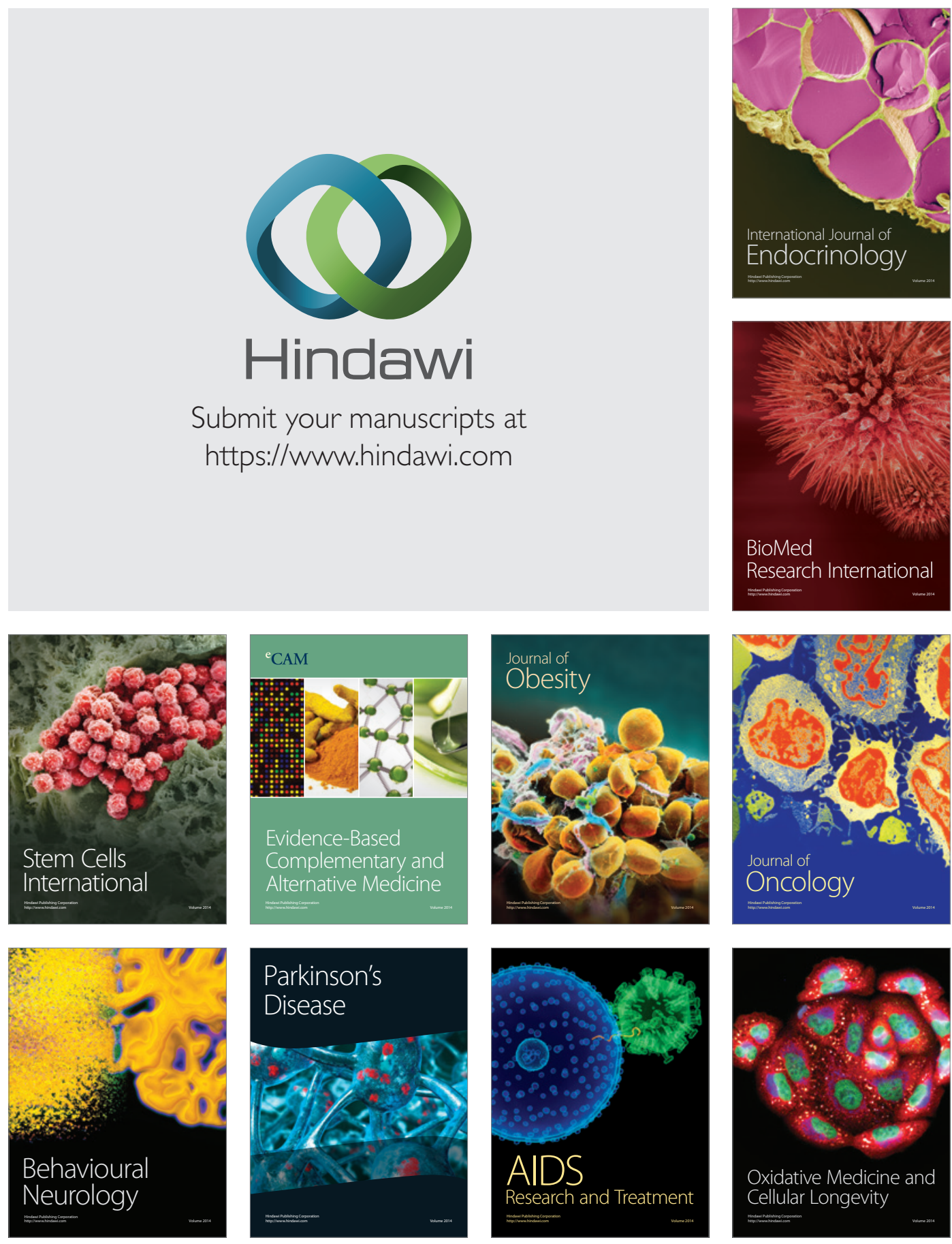